\title{
Self-Regulatory Mechanisms of Doping Intentions in Elite Athletes: The Role of Self-Determined Motivation in Sport
}

\section{Karine Corrion", Stéphanie Scoffier-Mériaux and Fabienne d'Arripe-Longueville}

Faculty of Sport Sciences, Laboratory of Human Motricity, Expertise, Sport, and Health EA 6312, Université Côte d'Azur, 261, route de Grenoble BP 3259, 06205 Nice cedex 03, France

"Corresponding author: Karine Corrion, Faculty of Sport Sciences, Laboratory of Human Motricity, Expertise, Sport, and Health EA 6312, Université Côte d'Azur, 261, route de Grenoble BP 3259, 06205 Nice cedex 03, France, Tel: +33 489836 616; Fax: +33 492296 53; E-mail: corrion@unice.fr

Received date: July 26, 2017; Accepted date: September 21, 2017; Published date: September 28, 2017

Copyright: $\odot 2017$ Corrion K, et al. This is an open-access article distributed under the terms of the Creative Commons Attribution License, which permits unrestricted use, distribution and reproduction in any medium, provided the original author and source are credited.

\begin{abstract}
Objective: Although research on the personal and psychosocial predictors of doping has been extensive, the factors related to the socio-cognitive self-regulatory mechanisms of doping remain unexplored. The aim of this study was to test an integrated multi-theory model examining the role of self-determined motivation in sport in the selfregulatory mechanisms of doping intentions in elite athletes.
\end{abstract}

Methods: A cross-sectional survey was employed. Two hundred and sixty-four elite athletes completed a survey that included measures of self-determination (autonomous vs. controlled), affective self-regulatory efficacy, resistive self-regulatory efficacy, moral disengagement, and doping intentions.

Results: Structural equation modeling showed that the model predicted $47.3 \%$ of the variance in doping intentions and indicated that both autonomous and controlled motivations were indirectly associated with doping intentions through the mediating role of affective self-regulatory efficacy, resistive self-regulatory efficacy, and moral disengagement.

Conclusion: Self-determination theory provides insight into how motivation in sport influences athletes' doping intentions through its impact on socio-cognitive self-regulatory mechanisms.

Keywords: Self-determination; Motivation; Doping intentions; Selfregulatory efficacy; Moral disengagement; Elite athletes; Sport

\section{Introduction}

The intensive training and competition of elite athletes may have a negative effect on their choice of strategies to enhance performance, notably by prompting them to consider the use of illegal drugs and methods (i.e., doping) [1]. Doping is defined as the occurrence of one or more violations of the ten anti-doping rules as set forth in Article 2.1 through Article 2.8 of the World Anti-Doping Agency Code (2015). Doping is against the rules and the spirit of fair play, and it is thus not a behavior that athletes can openly confess to. When athletes engage in doping in a hypothetical situation, however, they might feel less threatened about revealing their true intentions.

The sports psychology literature indicates that doping intentions, with athletes considering the pros and cons of the behavior, have mainly been studied from the perspectives of the theory of planned behavior (TPB) [2-5] and self-determination theory (SDT) $[3,4,6,7]$. Other studies based on Bandura's [8-10] social cognitive theory have shown that affective and resistive self-regulatory efficacy are related directly and/or through moral disengagement to transgressive behaviors in sport [11].

Although the research on the personal and psychosocial predictors of doping has been substantial, the factors related to the self-regulatory mechanisms of doping remain unexplored in elite sport. The purpose of this study was to arrive at a better understanding of doping through an integrated multi-theory model examining the role of selfdetermined motivation in sport in the self-regulatory mechanisms of doping intentions in elite sport.

\section{Self-Regulatory Mechanisms of Transgressive Behavior and Doping Intentions}

The findings of research based on the social cognitive theory of moral thought and action [8] suggest that moral disengagement, resistive self-regulatory efficacy and affective self-regulatory efficacy may be important constructs to take into account in the effort to better understand and explain doping. Self-regulatory mechanisms involve the capacity to observe, control and judge personal behavior and affective reactions in relation with personal, social or moral standards [8]. From this theoretical perspective, it is assumed that the capacity to self-regulate behavior will change and improve moral behavior. According to Bandura [8], moral disengagement is the process by which individuals convince themselves of the justification for their transgressive acts. Moral disengagement is thus related to a selfregulatory mechanism of cognitively restructuring inhumane activity. In this self-regulatory process, individuals cognitively restructure their inhumane conduct, their role in causing harm, the negative effects of their actions, or the targets of their transgressive acts $[8,10]$. For Bandura [8], personal standards can be violated without selfsanctioning through the use of the eight psychological maneuvers or mechanisms to morally disengage: moral justification (i.e., rendering detrimental conduct socially acceptable), advantageous comparison (i.e., comparing a reprehensible behavior to one that is far worse), 
euphemistic labeling (i.e., camouflaging pernicious activities as innocent or using sanitizing language), minimization or distortion of consequences (i.e., adopting harmful conduct toward others to attain personal goals or obtain rewards), attribution of blame (i.e., viewing oneself as a faultless victim driven to committing injurious acts by others), dehumanization (i.e., perceiving someone as not deserving to be treated like a human), displacement of responsibility and diffusion of responsibility (i.e., viewing actions as stemming from pressure or attributing detrimental behavior to several individuals acting together).

In the sports context, moral disengagement was first studied in relation to Ajzen's [12] theory of planned behavior constructs [2]. These authors showed that moral disengagement was positively associated with the intention to use doping substances and the selfreport use of these substances [2]. More recently, Bandura's [8] six mechanisms of moral disengagement have been applied to the sports doping context [13]. The positive relations between moral disengagement mechanisms and doping intentions have been consistently reported in both correlational research [13-17] and qualitative investigations [18].

Self-efficacy for social pressure resistance or resistive self-regulatory efficacy refers to the belief in one's ability to avoid or resist social pressure and solicitations to engage in transgressive behavior [19]. The protective role of this sense of self-regulatory efficacy for transgressive behaviors has been demonstrated in both daily life and sport. For instance, Bandura et al. showed that it negatively predicted adolescents' transgressive behaviors (e.g., physical and verbal aggression, theft, cheating, lying) directly $[9,10]$ and through moral disengagement [10]. Both cross-sectional and longitudinal studies have shown that resistive self-regulatory efficacy is related to the intentions of antisocial behavior in adolescents [20].

In the specific context of doping, most studies based on the TPB perspective have included measurements of perceived behavioral control and situational self-efficacy (i.e., temptation), this latter being an important predictor of doping intentions and the strongest mediator in motivation-intention [3,5]. Although these measures of self-efficacy are interesting, they do not directly inform about the capacity to resist social pressure. To date, resistive self-regulatory efficacy has been shown to be an indirect predictor of sports cheating variables through moral disengagement in adolescents. In a recent meta-analysis [1], self-regulatory efficacy was a negative predictor of doping intentions [3,5,17] in the sports context. Last, Ring and Kavussanu [16] showed that doping self-regulatory efficacy was associated with doping intentions both directly and indirectly through doping moral disengagement.

Bandura et al. [9] identified another type of self-regulatory efficacy related to affectivity, which has been shown to influence attentional, cognitive and motivational processes. Affect is often the basis for social ties and their durability, thereby influencing the course of lives [8]. This construct concerns both positive affect, like the expression of affection, enthusiasm or pleasure, and negative affect in reaction to provocation or rejection, like anger or rumination [9]. Perceived selfregulatory efficacy to manage these affective states has been considered to play a pivotal role in transgressive conduct. For example, Bandura et al. showed that negative affective self-regulatory efficacy was directly related to resistive self-regulatory efficacy, and both were directly associated with antisocial behavior [9]. In the sports context, GanoOverway et al. [21] showed the mediating role of affective selfregulatory efficacy in the relationship between perceptions of the sports climate and antisocial behavior. They observed that perceptions of a caring climate positively predicted affective self-regulatory efficacy, and that affective self-regulatory efficacy negatively predicted antisocial behavior. Last, d'Arripe-Longueville et al. [22] showed that affective self-regulatory efficacy was related to cheating variables both directly and through the mediating role of resistive self-regulatory efficacy in adolescents. However, the role of affective self-regulatory efficacy in doping intentions remains to be established.

The literature described above suggests that moral disengagement and self-regulatory mechanisms are important predictors of transgressive behaviors in sports contexts, and they have been associated with doping intentions. However, these socio-cognitive selfregulatory variables (i.e., resistive and affective self-regulatory efficacy, moral disengagement) have not yet been considered simultaneously and fully tested in the context of doping, specifically in elite athletes, who are particularly at risk for transgressions $[23,24]$.

\section{Self-Determination Theory, Self-Regulatory Mechanisms and Doping Intentions}

Another theoretical framework that may help to understand the self-regulatory mechanisms of doping is self-determination theory [25]. Ryan and Deci's theory of self-determination associates the type of motivation with the individual's degree of self-determination ranging from the non-self-determined to the self-determined. According to SDT, motivation is elicited by the satisfaction of three basic psychological needs (i.e., the need for autonomy, the need for competence, and the need for relatedness). As a result, research on SDT has traditionally focused on the predictive role of satisfaction of these three basic psychological needs for motivation. Intrinsic motivation is thus the result of the fulfilment of these three needs, while thwarting of these needs results in controlled motivation [25]. These authors also established a series of behavioral regulation stages (i.e., amotivation, external regulation, introjected regulation, identified regulation and intrinsic regulation).

According to SDT [25], motivation exists along a continuum with two broad types of motivation: (a) autonomous motivation, which includes intrinsic motivation and self-determined forms of extrinsic motivation (i.e., integrated regulation, identified regulation), and (b) controlled motivation (i.e., non-self-determined or controlled forms of extrinsic motivation characterized by external regulation, introjected regulation). Motivation is considered to be self-determined (i.e., autonomous) when an individual feels autonomous and behaves out of personal choice. Autonomous motivation represents behavior driven by intrinsic interest in or because of the value attached to the activity or by enjoyment of the activity itself. Conversely, motivation is not selfdetermined (i.e., controlled) when the individual acts under external pressures and controls. Controlled motivation is when behavior is regulated by a desire to obtain separable outcomes, with these actions emanating from self-imposed pressures (e.g., shame, pride), and to obtain a reward or comply with another person's demands. According to these authors, self-determined motivations are associated with more positive cognitive, affective and behavioral outcomes than extrinsic motivations because participating for personally valued reasons under one's own control is expected to be a more satisfying, positive experience, and participation in activity should be higher whether it is internally and volitionally driven $[25,26]$.

The literature indicates that among these adaptive patterns, autonomy improves self-regulation [25,27] and self-efficacy. For example, in the health behavior domain, autonomous motivation led 
to superior self-regulation in weight loss and weight loss maintenance and smoking cessation [28]. Studies that have examined doping variables from this theoretical point of view have shown indirect associations between self-determined motivation and doping. Hodge et al. reported that contexts that support self-determination variables (autonomous vs. controlled motivation) are associated with attitudes about antisocial and prosocial behavior [14] and drug-taking susceptibility through moral disengagement processes [7]. These authors showed that autonomous motivation was negatively associated with the doping intentions, both directly and through moral disengagement. Furthermore, Chan et al. found that the relationship between autonomous motivation in sport and intention for doping avoidance was completely mediated by perceived behavioral control, subjective norms, and autonomous motivation in doping avoidance, providing an additional understanding of the underlying psychological mechanisms.

The results from Barkoukis et al. [6] and Lazuras et al. [5] nevertheless suggested that motivational regulations did not inform the process leading to the formation of doping intentions when tested alongside other distal predictors such as achievement goals. These discrepant results can be explained by the use of different scales. For example, Hodge et al. [13] and Chan et al. used the Behavioral Regulation in Exercise Questionnaire [29-32], whereas Barkoukis et al. [6] and Lazuras et al. [5] used the Sport Motivation Scale [29].

In sum, the underlying mechanisms of the associations between self-determined motivation in sport and doping variables remain a key research question. Although socio-cognitive self-regulatory variables like affective and resistive self-regulatory efficacy are known to explain transgressive behaviors, they have not been considered simultaneously in relation to self-determined motivation, moral disengagement and doping in sport. Yet an examination of how these variables jointly operate may advance our knowledge on the psychological selfregulatory mechanisms underpinning doping intentions with selfdetermined motivation.

\section{Purpose and Hypotheses}

The current study was designed to advance our understanding of the mechanisms governing the use of doping in sport. Specifically, this study examined the role of self-determined motivation in sport (autonomous vs. controlled motivation) in the self-regulatory mechanisms of doping intentions in elite athletes. We did so by using an integrative model based on the tenets of SDT and self-regulatory mechanisms (i.e., affective and resistive self-regulatory efficacy and moral disengagement) of the socio-cognitive models of Bandura et al. $[9,10]$.

Given the research suggesting that self-determined motivation and self-regulatory efficacy constructs could be effectively joined to provide a more in-depth understanding of doping intentions, we expected that self-determined motivation would be associated with doping intentions directly and indirectly through various mediators (i.e., affective and resistive self-regulatory efficacy, and moral disengagement). Specifically, autonomous motivation was expected to be negatively related to doping intentions both directly and through self-regulatory efficacy variables and moral disengagement, whereas controlled motivation was expected to be positively related to doping intentions both directly and through the mediators. All of our hypotheses are presented in a hypothetical model (Figure 1).

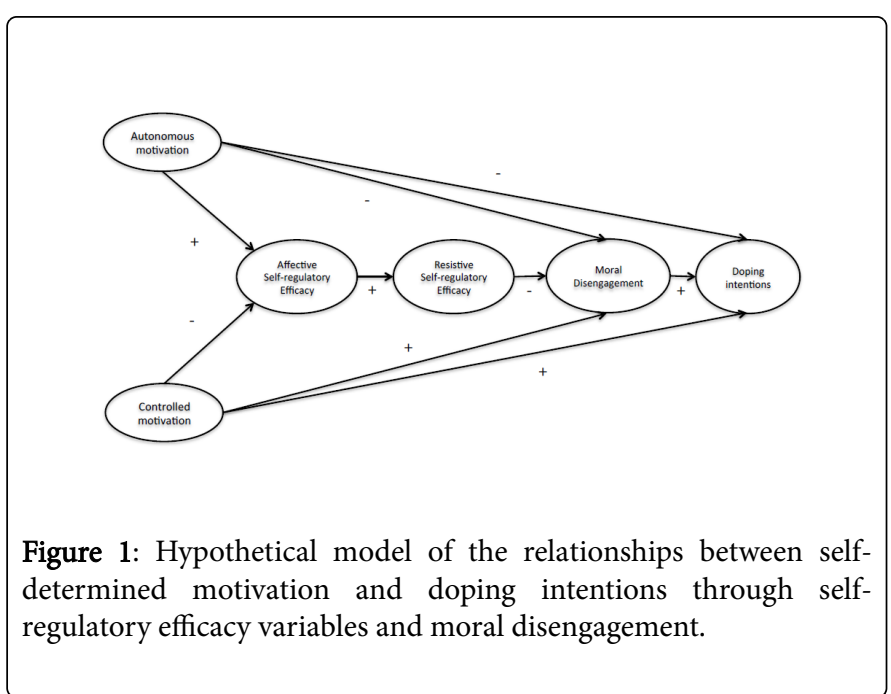

\section{Methods}

\section{Participants}

The study population was composed of 264 volunteer athletes (i.e., 182 men and 82 women) designated as "high-level" according to the French Sports Ministry. This sample size was deemed adequate given the number of independent variables to be included in the analyses [33]. Ages ranged from 15 to 22 years (Mage $=17.93 ; \mathrm{SD}=3.19$ ). Athletes were eligible to participate in the study if they met the following criteria: (a) currently training at one of three high-level training centers connected with the university, (b) participation in the Olympic Games or international competitions, and (c) membership in a federation. They practiced a wide range of sports, as follows: figure skating ( $\mathrm{N}=33 ; 4$ men and 29 women), football, $(\mathrm{N}=35 ; 35 \mathrm{men})$, basketball $(\mathrm{N}=23 ; 12$ men and 11 women), rugby ( $\mathrm{N}=89 ; 89$ men), cycling ( $\mathrm{N}=29 ; 26$ men and 3 women), swimming $(\mathrm{N}=11 ; 2$ men and 9 women), and other ( $\mathrm{N}=44 ; 17$ men and 27 women).

\section{Procedure}

The authors' University human ethics committee granted approval for this project prior to commencing the study. Both the directors of the training centers and the coaches agreed to our presence for the questionnaire sessions. The athletes were informed in advance of the dates and times. Standardized information and instructions for the questionnaires were given to the athletes to ensure optimal conditions and attentiveness on their part. We provided the following information: (a) participation in the studies was strictly voluntary and anonymity was ensured, (b) the questionnaires were not tests and therefore there were no right or wrong answers, and (c) the collected data would be used only for research and would remain strictly confidential (i.e., the consent form) and only sex and birthdates would be recorded. Parental authorization was obtained for all minors (under 16 years) and the other participants signed consent forms, in line with ethical standards. All questionnaire sessions were held in standardized conditions (i.e., small groups, paper, pencils, seating and no communication) or online. The sessions lasted 20 minutes at most. All participants were informed of their scores upon request. 


\section{Measures}

Five questionnaires were used to measure the following variables: (a) motivation in sport, (b) affective self-regulatory efficacy, (c) resistive self-regulatory efficacy, (d) moral disengagement, and (e) doping intentions.

Motivation in sport: The French version of the Behavioral Regulation in Exercise Questionnaire-2 (BREQ-2; Markland and Tobin, validated in French by Chamberland, Miquelon and Gareau $[32,34]$ was used. The BREQ-2 is composed of 19 items, measuring different types of behavioral regulation underlying the motivational continuum of SDT. Participants responded to the following instructions: "Below are some reasons why you participate in sport; please indicate how true each of the following statements is for you." The BREQ-2 includes five subscales designed to measure different types of motivation: (a) Intrinsic Motivation (IM; e.g., "I find sport a pleasurable activity"), (b) Identified Motivation (ID; e.g., "I value the benefits of my sport"), (c) Introjected Motivation (IJ; e.g., "I would feel ashamed if I quit"), (d) External Motivation (EX; e.g., "I exercise because others will not be pleased with me if I don't"), and (e) Amotivation (AM; e.g., "I wonder what's the point") presented on a Likert scale ranging from "Not true for me" (1) to "Very true for me" (6). For this study, the types of behavioral regulation were considered as one of two variables: autonomous or controlled motivation. We followed Hodge et al. formula to compute indicator scores for autonomous motivation and controlled motivation [14]. Scores for autonomous motivation (ID, IM) were calculated using the following formula: $2 \times(\mathrm{IM}+\mathrm{ID})$. Controlled motivation was calculated using $2 \times$ IJ+2 $\times$ EX [30]. A Confirmatory Factor Analysis (CFA) showed that the 19 -item model was significantly adjusted to the data [i.e., $\chi^{2}(74)$ $=163.43 ; \mathrm{CFI}=0.95 ; \mathrm{RMSEA}=0.065 ; \mathrm{CI}$ RMSEA $=0.051 / 0.081]$ with terms adaptation. The internal consistency of each subscale was satisfactory ( $\alpha \mathrm{IM}=0.82 ; \alpha \mathrm{ID}=0.80 ; \alpha \mathrm{IJ}=0.83 ; \alpha \mathrm{EX}=0.81$ ), as was the internal consistency for autonomous motivation $(\alpha \mathrm{AM}=0.81)$ and controlled motivation $(\alpha \mathrm{CM}=0.83)$.

Affective self-regulatory efficacy: Affective self-regulatory efficacy was evaluated using the items from the French version of the Social Skills Rating System (SSRS) [35-38], which was adapted to the sports context while preserving the highest semantic similarity to the original version. Sixteen items measured self-efficacy to regulate positive affect (5 items; e.g., "I feel capable of expressing my joy when positive things happen to me") and negative affect (12 items; e.g., "I feel capable of controlling myself when I am angry") on a Likert scale from "Not at all capable" (1) to "Completely capable" (6). In the present study, a CFA was used to examine the factorial structure of the scale. The results supported the hypothesized model [i.e., $\chi^{2}(110)=233.88$; CFI=0.91; RMSEA $=0.065$; CI RMSEA $=0.054 / 0.077]$. The internal consistency of the subscales was satisfactory ( $\alpha=0.88$ and $\alpha=0.86$, respectively, for positive affect and negative affect).

Resistive self-regulatory efficacy: Resistive self-efficacy was evaluated with the validated French version of Bandura et al. SelfRegulatory Scale [19], which was adapted for the sports context by Corrion et al. [39]. Six items measure self-efficacy to resist social pressure (RSRE; e.g., "How well do you resist pressure from others to cheat at your sport?") on a Likert scale from "Not at all capable" (1) to "Completely capable" (6). In the present study, the term "cheat" was replaced by "dope" in all items. CFA showed that the six-item model was significantly adjusted to the data [i.e., $\chi^{2}(8)=9.11$; CFI $=0.98$; RMSEA $=0.073$; CI RMSEA $=0.031 / 0.115]$. The scale demonstrated satisfactory internal consistency $(\alpha=0.90)$.
Moral Disengagement in Doping: Moral disengagement in doping was measured thanks to the French Short Moral Disengagement in Sport Scale [11] adapted to the doping context. The term "if I cheat" was replaced by "if I use banned substances." Three items measure the minimization of doping and their consequences (i.e., including euphemistic labeling and the minimization or distortion of consequences) and three items measure the projection of fault onto others (i.e., including attribution of blame, displacement of responsibility and diffusion of responsibility). An example of an item measuring the projection of fault onto others is "It's not my fault if I use banned substances when everybody else does". An example of an item measuring the minimization of doping and its consequences is "It's not serious if I use banned substances when it doesn't really hurt anyone." Participants were asked to respond to each of the statements by indicating how much they agreed with each statement on a Likert scale from "Do not at all agree" (1) to "Totally agree" (6). They were invited to keep their main competitive sport in mind when answering each question. In the present study, a CFA showed that the six-item model was significantly adjusted to the data in the doping context [i.e., $\chi^{2}(6)=18.19 ; \mathrm{CFI}=0.98$; RMSEA $=0.088$; CI RMSEA $\left.=0.043 / 0.136\right]$. The Cronbach alphas were 0.89 for the minimization of doping and their consequences, 0.81 for the projection of fault onto others.

Doping intentions: We employed an indirect approach to assess doping, namely, through the reported doping intentions in hypothetical scenarios by athletes. Scenarios have been used in previous doping research $[13,35]$ because they do not require athletes to reveal their true behavior and can refer to various doping situations [16]. We based our approach on both the series of scenarios developed by Zelli et al. [15] and the items used to measure doping intentions in past research $[3,36]$. The participating adolescents and young adults read five hypothetical scenarios concerning doping intentions. In particular, they were asked to imagine being the protagonist in interpersonal situations in which someone else offered or advised them to use performance-enhancing substances. The scenarios presented situations occurring in ecologically valid contexts, such as in a gym or on a sports team. A typical scenario is as follows:

"You are a member of a team that trains several times a week. One day at the end of training, one of your teammates pulls you aside and tells you about using a substance that, in very short time, made him stronger and more resistant to fatigue. He confesses that he has been able to improve his game performance using this product. He then asks you to follow him and offers you a sample, recommending that you use it in the coming days and reassuring you that it will work on you as well".

After reading each scenario, participants responded to a question about the intention of acting in the same way if they were in the same situation as the protagonist (i.e., doping intentions: "If you were in this situation, would you do what was suggested?") using a Likert scale ranging from "Not at all likely" (1) to "Totally likely" (6). In the present study, the Cronbach alpha was 0.88 .

\section{Data Analysis}

The data were analyzed using SPSS.22 and AMOS 20.0. The analysis authorized the replacement of missing values by using multiple imputation [37]. Several methods were used for the statistical analyses. We began with descriptive analyses (i.e., mean, standard deviation) and assessed the reliability of the questionnaires with Cronbach's alpha for internal consistency. Pearson bivariate correlations were computed 
Page 5 of 8

to assess the significance of the relationships between all variables (i.e., autonomous motivation, controlled motivation, affective selfregulatory efficacy, resistive self-regulatory efficacy, moral disengagement, and doping intentions). The hypotheses of the study were tested with a hierarchical linear regression analysis. We tested our hypothetical model and examined the relationships between selfdetermined motivation and doping intentions, as mediated by affective self-regulatory efficacy, resistive self-regulatory efficacy and moral disengagement with Structural Equation Modeling (SEM) using AMOS 20.0. Three indices were employed: chi-square $\left(\chi^{2}\right)$, the RootMean Square Error of Approximation (RMSEA), and the Bentler Comparative Fit Index (CFI). RMSEA values $\leq 0.08$ at $90 \%$ Confidence Interval (RMSEA CI 90\%) in combination with a value for CFI $\geq 0.90$ suggest an acceptable model fit $[40,41]$. The direct and indirect effects (i.e., comprising all the direct paths and all the indirect paths from one variable to another) and the total effects (i.e., comprising the direct paths and all indirect paths) for the structural model were calculated [40]. Methods of multiple mediation were adopted, and the different effects and their corresponding 95\% CIs were calculated to estimate both total and indirect effects for multiple mediator models, using bootstrapping and providing bias-corrected (BC) 95\% CIs. The number of bootstrap draws specified was 10,000 as recommended by Hayes.

\section{Results}

The means and standard deviations of the variables and the correlation matrix are presented in Table 1. Significant factor correlations ranged in magnitude from low to high and were in the theoretically expected directions. Affective self-regulatory efficacy was significantly related to resistive self-regulatory efficacy, moral disengagement and doping intentions. Resistive self-regulatory efficacy was significantly linked to moral disengagement and doping intentions. Higher levels of affective and resistive self-regulatory efficacy were associated with lower levels of moral disengagement and doping intentions.

A four-step hierarchical regression analysis identified the predictors of doping intentions as the dependent variable. In the first step, autonomous motivation and controlled motivation $(\beta=-0.130, \mathrm{p}<0.05$; $\beta=0.273, p<0.001$ ) significantly predicted doping intentions, $R^{2}=0.07$. Affective self-regulatory efficacy was added in the second step and significantly predicted doping intentions $(\beta=-0.122, p<0.05), R^{2}=0.08$ $\left(\Delta \mathrm{R}^{2}=0.01\right)$. In the third step, resistive self-regulatory efficacy was added and significantly predicted doping intentions $(\beta=-0.289$, $\mathrm{p}<0.001), \mathrm{R}^{2}=0.16(\Delta \mathrm{R} 2=0.08)$. Finally, moral disengagement was entered in the fourth step and significantly increased variance by $35 \%$ $\left(\Delta \mathrm{R}^{2}=0.19\right)$, Fchange $(5,264)=28.39, \mathrm{p}<0.001$, and had the strongest predictive effect on doping intentions. The predictors of doping intentions in each step are shown in Table 2.

\begin{tabular}{|c|c|c|c|c|c|c|c|c|c|}
\hline & M & SD & $\alpha$ & AutM & ContM & ASRE & RSRE & MD & DI \\
\hline AutM & $\begin{array}{c}20.4 \\
6\end{array}$ & 2.63 & 0.81 & - & $0.28^{\star *}$ & $0.14^{* *}$ & $0.13^{* *}$ & -0.13 & -0.05 \\
\hline $\begin{array}{c}\text { Cont } \\
M\end{array}$ & $\begin{array}{c}10.0 \\
6\end{array}$ & 2.89 & 0.83 & & - & $-0.15^{\star}$ & $\underset{*}{-0.16^{*}}$ & $\underset{* *}{0.19}$ & $\underset{* *}{0.24}$ \\
\hline ASRE & 4.55 & 0.61 & 0.87 & & & - & $0.23^{* *}$ & $\underset{\star \star}{-0.25}$ & -0.16 \\
\hline RSRE & 5.07 & 1.19 & 0.9 & & & & - & $\underset{\star \star}{-0.36}$ & -0.34 \\
\hline
\end{tabular}

\begin{tabular}{|c|c|c|c|c|c|c|c|c|c|}
\hline MD & 1.57 & 0.93 & 0.86 & & & & & - & 0.54 \\
$* *$
\end{tabular}

Table 1: Descriptive statistics and correlation matrix for Pearson's $r$ of measured variables $(\mathrm{N}=264)$.

\begin{tabular}{|c|c|c|c|c|c|c|c|}
\hline Step & Predictors & $\mathbf{F}$ & df & $\mathbf{R}^{2}$ & $\mathrm{DR}^{2}$ & $\beta$ & $\mathbf{t}$ \\
\hline \multirow{2}{*}{1} & AutM & \multirow{2}{*}{$10.02^{\star \star \star}$} & \multirow{2}{*}{2} & \multirow{2}{*}{0.07} & & $-0.130^{*}$ & -2.08 \\
\hline & ContM & & & & & $0.273^{\star \star *}$ & 4.38 \\
\hline \multirow{3}{*}{2} & AutM & \multirow{3}{*}{$7.80^{\star * *}$} & \multirow{3}{*}{3} & \multirow{3}{*}{0.08} & \multirow{3}{*}{0.01} & -0.106 & -1.68 \\
\hline & ContM & & & & & $0.250^{* * *}$ & 3.95 \\
\hline & ASRE & & & & & $-0.110^{*}$ & -1.78 \\
\hline \multirow{4}{*}{3} & AutM & \multirow{4}{*}{$12.57^{\star \star \star}$} & \multirow{4}{*}{4} & \multirow{4}{*}{0.16} & \multirow{4}{*}{0.08} & -0.064 & -1.05 \\
\hline & ContM & & & & & $0.204^{* *}$ & 3.32 \\
\hline & ASRE & & & & & -0.055 & -0.91 \\
\hline & RSRE & & & & & $-0.296^{\star * *}$ & -4.97 \\
\hline \multirow{5}{*}{4} & AutM & \multirow{5}{*}{$26.64^{\star \star \star}$} & \multirow{5}{*}{5} & \multirow{5}{*}{0.34} & \multirow{5}{*}{0.18} & -0.01 & -0.18 \\
\hline & ContM & & & & & $0.130^{*}$ & 2.35 \\
\hline & ASRE & & & & & 0.013 & 0.24 \\
\hline & RSRE & & & & & $-0.161^{* *}$ & -2.9 \\
\hline & MD & & & & & $0.467^{\star * *}$ & 8.34 \\
\hline
\end{tabular}

Notes: AutM: autonomous motivation; ContM: controlled motivation; ASRE: affective self-regulatory efficacy; RSRE: resistive self-regulatory efficacy; MD: moral disengagement. ${ }^{*} p<0.05,{ }^{* *} p<0.01,{ }^{* \star *} p<0.001$.

Table 2: Psychosocial predictors of doping intentions.

We then tested the hypothetical model presented in Figure 1 through SEM. Our model tested the relationships between selfdetermined motivation (i.e., autonomous or controlled) and doping intentions, through the variables of self-regulatory efficacy (i.e., affective and resistive self-regulatory efficacy) and moral disengagement. The model showed satisfactory goodness of fit $\left[\chi^{2}(46)\right.$ $=66.62 ; \mathrm{CFI}=0.98 ; \mathrm{RMSEA}=0.04$; CI RMSEA 0.01/0.06]. It explained $47.3 \%$ of the variance in doping intentions. Figure 2 displays the regression coefficients significant at 0.05 and explained factor variances in the mediation model. 


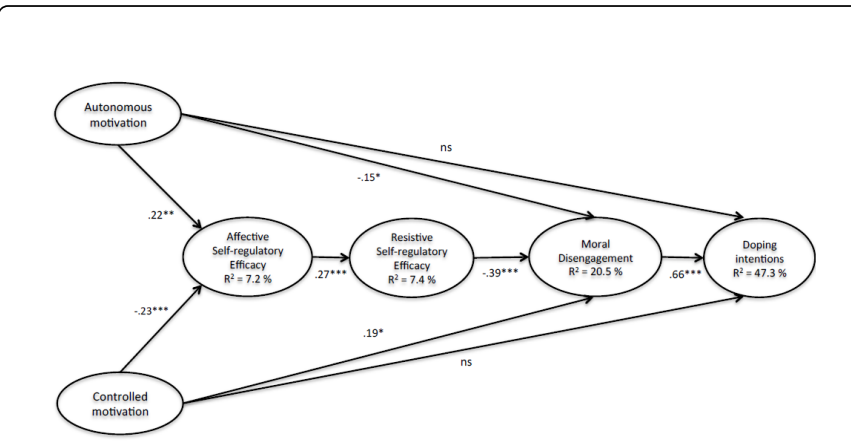

Figure 2: Model of the relationships between self-determined motivation and doping intentions, through self-regulatory efficacy variables and moral disengagement. The values of the coefficients between variables are standardized. ${ }^{*} \mathrm{p}<0.05 ;{ }^{* *} \mathrm{p}<0.01 ;{ }^{* *} \mathrm{p}<0.001$.

The fit indices, estimates, and effect decomposition of the mediation analyses are presented in Table 3. Mediation analysis revealed the indirect effects of autonomous motivation in sport on moral disengagement through the self-regulatory efficacy variables. The effect of autonomous motivation in sport on doping intention was mediated by affective self-regulatory efficacy, resistive self-regulatory efficacy, and moral disengagement. However, the direct effect of autonomous motivation in sport on doping intentions was not significant.

\begin{tabular}{|c|c|c|c|c|c|c|c|}
\hline & $\begin{array}{l}\text { Mediato } \\
\text { rs }\end{array}$ & $\begin{array}{l}\text { IV } \quad> \\
\text { mediato } \\
\text { r(s) }\end{array}$ & $\begin{array}{l}\text { Mediato } \\
\text { r(s) } \rightarrow \\
\text { DV }\end{array}$ & $\begin{array}{l}\text { Total } \\
\text { effect }\end{array}$ & $\begin{array}{l}\text { Direct } \\
\text { effect }\end{array}$ & $\begin{array}{l}\text { Indirect } \\
\text { effect }\end{array}$ & $\begin{array}{l}95 \% \\
\mathrm{Cl}\end{array}$ \\
\hline $\begin{array}{r}\text { AutM } \\
\rightarrow>\text { MD }\end{array}$ & $\begin{array}{l}\text { ASRE- } \\
\text { RSRE }\end{array}$ & $\begin{array}{l}0.22^{\star *} / \\
0.27^{* *}\end{array}$ & $-0.39^{* * *}$ & $-0.17^{* \star}$ & $-0.15^{*}$ & -0.02 & $\begin{array}{l}(-0.072 \\
\text { to } \\
-0.008 \\
)\end{array}$ \\
\hline \multirow{2}{*}{$\begin{array}{l}\text { AutM } \\
\rightarrow \text { DI }\end{array}$} & MD & $0.15^{*}$ & $0.66^{\star \star \star}$ & -0.09 & -0.02 & -0.11 & $\begin{array}{c}(-0.089 \\
\text { to } \\
0.184)\end{array}$ \\
\hline & $\begin{array}{l}\text { ASRE- } \\
\text { RSRE- } \\
\text { MD }\end{array}$ & $\begin{array}{l}0.22^{* * /} \\
0.27^{* * \star /} \\
-0.39^{\star * \star}\end{array}$ & $0.66^{\star \star \star}$ & & & & $\begin{array}{l}(-0.208 \\
\text { to } \\
-0.015 \\
)\end{array}$ \\
\hline $\begin{array}{l}\text { ContM } \\
->\text { MD }\end{array}$ & $\begin{array}{l}\text { ASRE- } \\
\text { RSRE }\end{array}$ & $\begin{array}{l}-0.23^{* \star \star} / \\
0.27^{\star \star \star}\end{array}$ & $-0.39^{* * *}$ & $0.22^{* *}$ & $0.19^{*}$ & 0.03 & $\begin{array}{l}(0.007 \\
\text { to } \\
0.073)\end{array}$ \\
\hline $\begin{array}{l}\text { ContM } \\
\text {-> DI }\end{array}$ & MD & $0.19^{*}$ & $0.66^{\star \star \star}$ & - & - & - & $\begin{array}{l}(-0.06 \\
6 \text { to } \\
0.262)\end{array}$ \\
\hline \multirow{2}{*}{$\begin{array}{l}\text { ContM } \\
->\text { DI }\end{array}$} & \multirow{2}{*}{$\begin{array}{l}\text { ASRE- } \\
\text { RSRE- } \\
\text { MD }\end{array}$} & $\begin{array}{l}-0.23^{* \star \star} / \\
0.27^{* \star \star} /\end{array}$ & \multirow[t]{2}{*}{$0.66^{* * *}$} & \multirow[t]{2}{*}{$0.25^{\star *}$} & \multirow[t]{2}{*}{0.11} & \multirow[t]{2}{*}{0.14} & \multirow{2}{*}{$\begin{array}{l}(0.021 \\
\text { to } \\
0.226)\end{array}$} \\
\hline & & $-0.39^{* * *}$ & & & & & \\
\hline
\end{tabular}

Notes: IV: independent variable; DV: dependent variable; AutM: autonomous motivation; ContM: controlled motivation; ASRE: affective self-regulatory efficacy; RSRE: resistive self-regulatory efficacy; MD: moral disengagement; DI: doping intentions; $95 \% \mathrm{Cl}$ : lower and upper bound of bias-corrected $95 \%$ confidence interval with 10.000 bootstrap samples. ${ }^{*} p<0.05, \quad{ }^{* *} p<0.01$, ${ }^{* * *} p<0.001$.

Table 3: Results of multiple mediation analyses for the final structural model.
Furthermore, the results indicated that the direct effect of controlled motivation in sport on doping intentions was not significant. Mediated analyses revealed that: (a) the effects of controlled motivation in sport on moral disengagement were significantly mediated by affective selfregulatory efficacy and resistive self-regulatory efficacy, and (b) the effect of controlled motivation in sport on doping intentions was mediated by affective self-regulatory efficacy, resistive self-regulatory efficacy, and moral disengagement. Finally, the results indicated a significant direct effect of autonomous and controlled motivation in sport on moral disengagement.

\section{Discussion}

The main objective of this study was to identify the role of selfdetermined motivation in the self-regulatory mechanisms of doping intentions in elite athletes. We used an integrative model to assess the direct and indirect effects of self-determined motivation in sport on these self-regulatory mechanisms of doping intentions. The findings of this research showed a good empirical fit to the structural model specifying how self-determined motivation operates in concert with the self-regulatory mechanisms of doping, which explained $47.3 \%$ of the variance of doping intentions.

We expected autonomous motivation in sport to be negatively related to doping intentions both directly and through self-regulatory efficacy variables and moral disengagement, while controlled motivation was expected to demonstrate positive relationships with doping intentions both directly and through the mediators. Our results showed that autonomous motivation and controlled motivation in sport were only indirectly linked to doping intentions. The lack of a significant direct effect from motivation to doping intentions is similar to the findings reported by Barkoukis et al. [3] and Lazuras et al. [5]. This suggests that the intention to engage in doping is irrelevant to adopting specific self-determination motivation in sport. However, these associations (i.e., motivation in sport to doping) were mediated by self-regulatory efficacy variables and moral disengagement, providing support for our hypothesis. First, controlled motivation was positively related to doping intentions through moral disengagement, while autonomous motivation was negatively linked to doping intentions through moral disengagement. These findings are consistent with previous studies $[7,14,15]$ that have reported that contexts supporting controlled motivation are associated with attitudes about antisocial behaviors and drug-taking susceptibility or doping intentions through moral disengagement processes. More generally, this relationship is consistent with self-determination theory [25] and the findings of previous studies that have clearly established the maladaptive set of responses of controlled motivation in sport [42,43]. Higher controlled motivation in athletes may also be related to the general context of commercialization, globalization, and culture that has led to greater pressure on athletes to win or attain financial rewards and has favored doping as a way to perform in sport [44].

Furthermore, based on the notion that autonomy improves selfregulation and self-efficacy, we anticipated that self-determined motivation would act as a proximal predictor of affective and resistive self-regulatory efficacy. As expected, both autonomous motivation and controlled motivation were linked to doping intentions through affective and resistive self-regulatory efficacy and moral disengagement. Specifically, autonomous motivation was positively linked to affective self-regulatory efficacy, and the latter was positively related to resistive self-regulatory efficacy, which in turn was negatively linked to moral disengagement. In contrast, controlled motivation was 
negatively linked to affective self-regulatory efficacy. These findings extend the literature on the self-regulatory mechanisms governing transgressive behavior in two ways. First, they show that Bandura's social cognitive model, which was first tested in daily life $[9,10]$ and then applied to the sports context [11], can be extended to the specific context of doping in sport. Essentially, the more elite athletes are able to control their affect and responses to social pressure, the less likely they are to morally disengage and have doping intentions. Second, these findings provide support for the tenets of self-determination theory by evidencing the positive role of autonomous motivation in self-regulatory mechanisms, and the negative role of controlled motivation. They provide support for earlier results showing that autonomy improves self-regulation [25,27] and self-efficacy [45], and extend them to the context of doping in sport. More generally, our study provides new insight into the underlying psychological mechanisms by which self-determined motivation contributes to the explanation of doping intentions. While previous studies have evidenced the mediating role of perceived behavioral control $[36,46]$, the present study highlights the role of affective and resistive selfregulatory efficacy in this relationship.

Several potential limitations should be considered when interpreting these findings. First, the measure of motivation in sport was limited to the use of the BREQ-2 and the moral disengagement scale. Second, the data for our quite sensitive variables were selfreported and may thus have been subject to social desirability bias. Future research could include more implicit types of measures to overcome this bias [47]. Third, the generalizability of the results is limited by age and level of competitive sport. For example it must be acknowledged that a maximum of 22 years old was not representative for international sport. The study could thus be replicated in samples of lower-level athletes and various ages. Fourth, the cross-sectional design of this study is subject to the omitted variable problem. Finally, a large proportion of the variance in doping intention was not explained by the variables assessed. Future studies should thus consider expanding the variables that were not assessed to better explain doping intentions.

Therefore, experimental and longitudinal studies should be carried out to determine whether our findings can be replicated. For example, designs assessing variables over multiple time points, as advocated by Gucciardi et al. [48], and experimental studies to examine the influence of a doping prevention program designed to enhance selfregulation skills (e.g., the effects of increased affective and resistive selfregulatory efficacy and decreased moral disengagement on doping intentions) are important avenues for future research. Moreover, more research should be conducted to expand the present findings. Studies could be conducted to examine (a) the role of the determination continuum in the self-regulatory mechanisms (with the use of the Behavioral Regulation in Exercise Questionnaire-6 (BREQ-6) and (b) the joint role of the mediators reported in the literature: perceived behavioral control and the self-regulatory mechanisms, on doping variables.

\section{Perspectives}

In closing, the present study has interesting practical implications. Our findings suggest that effective doping prevention interventions should take motivation and self-regulatory mechanisms (affective and resistive self-regulatory efficacy) into account to better empower athletes and their entourage to resist unethical temptations and pursue performance goals through legal substances and methods.
Encouraging the development of self-determined motivation in athletes might be a potential route to ensuring that these athletes are able to effectively regulate the intention to engage in transgressive behavior (doping, cheating). It therefore could become a key element in future anti-doping education. These findings provide interesting food for thought for the design of future intervention programs, specifically for the type of motivational climate that should be created (supporting autonomy) and the type of control to be developed in the athletes (related to self-regulatory efficacy mechanisms).

\section{Conclusion}

The current study is the first to present an integrative theoretical model to identify the role of self-determined motivation in the selfregulatory mechanisms of doping intentions in elite sport. The findings showed that autonomous and controlled motivations are indirectly associated with doping intentions through the mediating role of affective self-regulatory efficacy, resistive self-regulatory efficacy and moral disengagement. Our study provides new answers to questions about the psychological mechanisms underlying the relationship between self-determined motivations and doping intentions.

\section{Acknowledgement}

This study was financially supported by a grant from the WADA. The authors are grateful to the athletes for their participation.

\section{References}

1. Ntoumanis N, Ng JYY, Barkoukis V, Backhouse S (2014) Personal and psychosocial predictors of doping use in physical activity settings: A meta-analysis. Sports Med 44: 1603-1624.

2. Lucidi F, Zelli A, Mallia L, Grano C, Russo PM, et al. (2008) The socialcognitive mechanisms regulating adolescents' use of doping substances. J Sports Sci 26: 447-456.

3. Barkoukis V, Lazuras L, Tsorbatzoudis H, Rodafinos A (2013) Motivational and social cognitive predictors of doping intentions in elite sports: An integrated approach. Scand J Med Sci Sports 23: 330-340.

4. Chan DKC, Dimmock JA, Donovan RJ, Hardcastle SJ, Lentillon-Kaestner $\mathrm{V}$, et al. (2015) Self-determined motivation in sport predicts anti-doping motivation and intention: A perspective from the trans-contextual model. J Sci Med Sport 18: 315-322.

5. Lazuras L, Barkoukis V, Rodafinos A, Tzorbatzoudis H (2015) Toward an integrative model of doping use: An empirical study with adolescent athletes. J Sport Exerc Psychol 37: 37-50.

6. Barkoukis V, Lazuras L, Tsorbatzoudis H, Rodafinos A (2011) Motivational and sportspersonship profiles of elite athletes in relation to doping behavior. Psychol Sport Exerc 12: 205-212.

7. Hodge K, Hargreaves EA, Gerrard D, Lonsdale C (2013) Psychological mechanisms underlying doping attitudes in sport: Motivation and moral disengagement. J Sport Exerc Psychol 35: 419-432.

8. Bandura A (1991) Social cognitive theory of moral thought and action. In: WM Kurtines, JL Gewirtz (eds.), Handbook of moral behavior and development: Theory, research and applications. Lawrence Erlbaum Associates, Hillsdale, New Jersey. pp: 45-103

9. Bandura A, Caprara GV, Barbaranelli C, Gerbino M, Pastorelli C (2003) Role of affective self-regulatory efficacy in diverse spheres of psychosocial functioning. Child Dev 74: 769-782.

10. Bandura A, Caprara GV, Barbaranelli C, Pastorelli C, Regalia C (2001) Sociocognitive self-regulatory mechanisms governing transgressive behaviors. J Perso Soc Psychol 80: 125-135.

11. Arripe-Longueville F (d'), Corrion K, Scoffier S, Roussel P, Chalabaev A (2010) Socio-cognitive self-regulatory mechanisms governing judgments 
of the acceptability and likelihood of sport cheating. J Sport Exerc Psychol 32: 595-618.

12. Ajzen I (1991) The theory of planned behavior. Organ Beh Hum Decis Process 50: 179-211.

13. Kavussanu M, Hatzigeorgiadis A, Elbe AN, Ring C (2016) The moral disengagement in doping scale. Psychol Sport Exerc 24: 188-198.

14. Hodge K, Lonsdale C (2011) Prosocial and antisocial behavior in sport: The role of coaching style, autonomous vs. controlled motivation, and moral disengagement. J Sport Exerc Psychol 33: 527-547.

15. Zelli A, Mallia L, Lucidi F (2010) The contribution of interpersonal appraisals to a social-cognitive analysis of adolescents' doping use. Psychol Sport Physic Exerc 11: 304-311.

16. Ring C, Kavussanu M (2017) The role of self-regulatory efficacy, moral disengagement and guilt on doping likelihood: A social cognitive theory perspective. J Sports Sci 8: 1-7.

17. Mallia L, Lazuras L, Barkoukis V, Brand R, Baumgarten F, et al. (2016) Doping use in sport teams: The development and validation of measures of team-based efficacy beliefs and moral disengagement from a crossnational perspective. Psychol Sport Exerc 25: 78-88.

18. Boardley ID, Grix J, Dewar A (2014) Moral disengagement and associated processes in performance enhancing drug use: A national qualitative investigation. J Sport Sci 32: 836-844.

19. Bandura A, Barbaranelli C, Caprara, GV, Pastorelli C (1996) Multifaceted impact of self-efficacy beliefs on academic functioning. Child Dev 67: 1206-1222.

20. Caprara GV, Regalia C, Bandura A (2002) Longitudinal impact of perceived self-regulatory efficacy on violent conduct. Eur Psychol 7: 63-69.

21. Corrion K, Scoffier S, Gernigon C, Cury F, Arripe-Longueville F(d') (2010) Développement et validation d'une Echelle Courte mesurant le Désengagement Moral en Sport (ECDMS) [Development and factorial validity of a Short Moral Disengagement in Sport Scale]. L'Encéphale 36: 495-503.

22. Gano-Overway LA, Newton M, Magyar TM, Fry MD, Kim MS, et al. (2009) Influence of caring youth sport contexts on efficacy-related beliefs and social behaviors. Dev Psychol 45: 329-340.

23. Kavussanu M (2012) Moral behavior in sport. In: Murphy S (ed.), The Oxford handbook of sport and performance psychology. Oxford University Press, Oxford. pp: 364-383.

24. Kavussanu M (2014) Moral behavior. In Eklund RJ, Tenenbaum GT (eds.), Sage encyclopedia of sport and exercise psychology. Sage, Los Angeles, CA.

25. Ryan RM, Deci EL (2000) Self-determination theory and the facilitation of intrinsic motivation, social development, and well-being. American Psycho 55: 68-78.

26. Deci EL, Ryan RM (1985) Intrinsic motivation and self-determination in human behavior. Plenum, New York.

27. Legault L, Inzlicht M (2013). Self-determination, self-regulation and the brain: Autonomy improves performance by enhancing neuroaffective responsiveness to self-regulation failure. J Perso Social Psychol 105: 123-138.

28. Williams GC, Niemiec CP, Patrick H, Ryan RM, Deci EL (2009) The importance of supporting autonomy and perceived competence in facilitating long-term tobacco abstinence. Ann Behav Med 37: 315-324.

29. Pelletier L, Rocchi MA, Vallerand RJ, Deci EL, Ryan RM (2013) Validation of the revised sport motivation scale (SMS-II). Psychol Sport Exerc 14: 329-341

30. Lonsdale C, Hodge K, Rose E (2009) Athlete burnout in elite sport: A selfdetermination perspective. J Sports Sci 27: 785-795.
31. Lonsdale C, Hodge K, Rose EA (2008) The Behavioral Regulation in Sport Questionnaire (BRSQ): Instrument development and initial validity evidence. J Sport Exerc Psychol 30: 323-355.

32. Chamberland P, Miquelon P, Gareau A (2013) French validation of the integrated motivation scale for the Behavioural Regulation in Exercise Questionnaire II (BREQ-II). Poster presented at the 74th annual convention of the Canadian Psychological Association, Quebec City, Canada.

33. Tabachnick BG, Fidell LS (2001) Using multivariate statistics (4th ed.), M.A. Allyn, Boston, Bacon.

34. Markland D, Tobin VA (2004) Modification of the behavioral regulation in exercise questionnaire to include an assessment of amotivation. J Sport Exerc Psychol 26: 191-196.

35. Huybers T, Mazanov J (2012) What would Kim do? A choice study of projected athlete doping considerations. J Sport Manag 26: 322-334.

36. Lazuras L, Barkoukis V, Rodafinos A, Tzorbatzoudis H (2010) Predictors of doping intentions in elite-level athletes: A social cognition approach. J Sport Exerc Psychol 32: 694-710.

37. Li P, Stuart EA, Allison DB (2015) Multiple imputation: A flexible tool for handling missing data. J Am Med Assoc 314: 1966-1967.

38. Corrion K, Scoffier-Mériaux S, Arripe-Longueville F(d') (2016) Développement et validation en langue française de l'Echelle de Mesure de l'Efficacité AutoRégulatrice des Affects en Sport (EARAS) [Development and French validation of the Affective Self-Regulatory in Sport Scale]. Psychol Fr 61: 319-332.

39. Corrion K, Gernigon C, Debois N, Arripe-Longueville F(d') (2013) Factor validity and reliability of the resistive self-regulatory in sport scale (RSRESS) in a French sample. Int J Sport Psychol 44: 128-144.

40. Byrne BM (2005) Factor analytic models: Viewing the structure of an assessment instrument from three perspectives. J Pers Assess 85: 17-32.

41. Hu LT, Bentler PM (1999) Cutoff criteria for fit indexes in covariance structure analysis: Conventional criteria versus new alternatives. Struct Equ Modeling 6: 1-55.

42. Rucker DD, Preacher KJ, Tormala ZL, Petty RE (2011) Mediation analysis in social psychology: Current practices and new recommendations. Social and Perso Psychol Compass 5: 359-371.

43. Ntoumanis N, Mallet C (2014) Motivation in sport: A self-determination theory perspective. In: Papaioannou A, Hackfort D (eds.) Routledge Companion to Sport and Exercise Psychology: Global perspectives and fundamental concepts. Taylor and Francis, UK. pp: 67-82.

44. Stewart B, Smith ACT (2008). Drug use in sport: Implications for public policy. J Sport Soc Issues 32: 278-298.

45. Sweet SN, Fortier MS, Strachan SM, Blanchard CM (2012) Testing and integrating self-determination theory and self-efficacy theory in a physical activity context. Can Psychol 53: 319.

46. Chan DK, Hardcastle SJ, Lentillon-Kaestner V, Donovan RJ, Dimmock JA, et al. (2014) Athletes' beliefs about and attitudes towards taking banned performance-enhancing substances: A qualitative study. Sport Exerc Perf Psychol 3: 241-257.

47. Brand R, Melzer M, Hagemann N (2011) Towards an implicit association test (IAT) for measuring doping attitudes in sports. Data-based recommendations developed from two recently published tests. Psychol Sport Exerc 12: 250-256.

48. Gucciardi D, Jalleh G, Donovan R (2010) Does social desirability influence the relationship between doping attitudes and doping susceptibility in athletes? Psychol Sport Exerc 11: 479-486. 